\title{
Por uma Didática Não-Fascista: problematizando a formação docente à educação básica
}

\author{
Samilo Takara' \\ Teresa Kazuko Teruya' \\ 'Universidade Estadual de Maringá (UEM), Maringá/PR - Brasil
}

RESUMO - Por uma Didática Não-Fascista: problematizando a formação docente à educação básica. $O$ presente artigo trata de como a didática na educação básica pode ser pensada por meio da noção de vida não-fascista discutida por Michel Foucault (1991) tratando dos modos de viver na sociedade contemporânea. Em Anti-Édipo: Introdução à vida não-fascista, prefácio à versão norte-americana da obra de Deleuze e Guattari, o autor apresenta uma época de instabilidades e mudanças sociais, culturais e políticas. Nossa questão norteadora é: de que modo utilizamos a didática na contemporaneidade? Interessados/as em pensar a educação escolar propomos a desestruturação de um projeto moderno de didática no intuito de pensar outras possibilidades na atuação de professores/as.

Palavras-chave: Educação. Mídias. Didática. Formação Docente.

ABSTRACT - For a Non-Fascist Didactics: questioning the training of teachers for the K-12 education. This article is about how the didactics in K-12 education can be thought through the notion of non-fascist life discussed by Michel Foucault (1991) when discussing the ways of life in the contemporary society. In Anti-Oedipus: Introduction to Non-Fascist Life, preface to the North American version of the work of Deleuze and Guattari, the author presents a time of instability and social, cultural and political changes. Our guiding question is: How can we use the didactics in contemporary times? Interested in thinking about education, we suggest the disintegration of a modern project of didactics in order to think about other possibilities in the work of teachers.

Keywords: Education. Media. Didactics. Teacher Training.

Educação \& Realidade, Porto Alegre, v. 40, n. 4, p. 1169-1189, out./dez. 2015.1169 http://dx.doi.org/10.1590/2175-623646035 


\section{Introdução}

A Didática vem do grego tecné didaktiké que significa arte ou técnica de ensinar. Esse conceito mudou historicamente e é uma das atribuições entre os campos de atuação e conhecimento da formação pedagógica. Trata-se de uma disciplina que estuda as teorias pedagógicas e seus procedimentos de ensino em diferentes contextos sociais, culturais, econômicos e históricos. Esta disciplina oferece uma formação para que os/as professores/as pensem suas práticas no contexto da sala de aula, os métodos e os planos de ensino em articulação com as políticas públicas internacionais e nacionais, a gestão da escola, as metodologias de ensino e as práticas de formação social, cultural e intelectual dos/as alunos/as.

Entre os conteúdos ministrados na disciplina há a problematização dos conceitos de educação, de aluno/a, de professor/a; dos métodos e planejamentos de ensino; dos projetos de trabalho e da avaliação de ensino e aprendizagem para pensarmos como as teorias e as práticas pedagógicas organizam os procedimentos didáticos. Nossa questão norteadora é: Em uma época de instabilidades e mudanças sociais, culturais e políticas, de que modo podemos pensar a Didática na Educação Básica? Para problematizar essa pergunta, nos embasamos nas discussões pertinentes aos Estudos Culturais para pensar a formulação da Didática como área de formação e de atuação dos profissionais da Educação Básica.

Esta discussão perpassa os Estudos Culturais, porque se torna possível questionar os sentidos e as práticas da Didática no momento em que a Cultura torna-se um conceito em disputa. Desarticulando a noção de kultur como práticas, objetos e exercícios que denotam o melhor produzido pela humanidade, a antropologia, a linguística e a filosofia romperam com um olhar monocultural. Somando a esta problemática:

[...] os Estudos Culturais foram particularmente eficientes no sentido de desconstruir - ou, às vezes, no sentido de até detonar - o conceito moderno e nos mostrar a produtividade de entendermos que é melhor falarmos de culturas em vez de falarmos Cultura (Veiga-Neto, 2003, p. 11).

Veiga-Neto (2003) contribui para esta análise usando o termo culturas, pois desnaturaliza as práticas educacionais como a didática. A perspectiva teórico-política dos Estudos Culturais nos oferecem condições de interpretarmos as trajetórias que nos localizam como sujeitos de possibilidades e nos permitem analisar as condições educacionais “[...] para resistir, para desarmar, reverter, subverter o que somos e o que fazemos” (Veiga-Neto, 2003, p. 7). Para Nelson, Treichler e Grossberg (2008), este eixo explicativo propõe olhares epistemológicos que marcam a diferença e que contribuem para repensar a educação, seus sentidos e suas interpretações nas culturas.

1170 Educação \& Realidade, Porto Alegre, v. 40, n. 4, p. 1169-1189, out./dez. 2015. 
Desse modo, apresentamos a noção de Didática entre os autores que constituíram o campo e nos focamos nas demandas da educação contemporânea para pensar a formação docente. Discutimos a escola nos contextos da contemporaneidade e sua relação com as mídias, além das contribuições dos diferentes discursos acerca de educação e sociedade na construção de uma perspectiva de atuação de professores/as. Pensar a Didática na Educação Básica é uma preocupação da formação docente para problematizar as instituições de ensino, suas demandas e suas potencialidades para a formação de alunos/as que discutem, problematizam e interferem em suas realidades sociais, culturais, políticas e econômicas.

\section{A Constituição da Didática}

A Educação como área de estudos tem fornecido elementos para pensarmos os contextos da produção material, cultural, política e intelectual que perpassam as compreensões de global, nacional, regional, local, bem como as noções de minuto, hora, dia, ano e século. Espaço e tempo são conceitos que foram construídos socialmente e fazem-se necessários para problematizar a função educacional em diversos momentos históricos e localidades geográficas. Cada pedagogo, filósofo e pensador da Educação contribuem na problematização das necessidades de seu tempo e seu espaço ao referir-se à Didática. A título de contextualização, citamos escritos didáticos e pedagógicos produtores e produzidos em diferentes tempos históricos, que contribuem para pensar a proposta de uma didática não-fascista. Entretanto, este texto não esgota as diferentes vertentes e contribuições de outros autores e pedagogos para a constituição deste campo educacional. Desse modo, apresentamos olhares acerca da didática pertinentes para atualizarmos os sentidos sobre essa perspectiva e pensarmos na formação docente.

No século XVII encontramos as marcas da mudança do paradigma teocêntrico para o antropocêntrico. Comenius faz referências ao Deus cristão e as escrituras de seus profetas. Ele atribui à Educação a tarefa de "[...] providenciar para que as suas mentes sejam imbuídas de um verdadeiro conhecimento de Deus, de si mesmas e da multiplicidade das coisas; para que se habituem a ver a luz à luz de Deus, e a amar e a venerar, acima de tudo, o Pai das luzes" (Comenius, 2001, p. 39).

A arte de ensinar, para Comenius, expressava o ofício medieval ou o artesanato, mas ao mesmo tempo a manufatura despontava no processo de desagregação das oficinas medievais. O professor deveria imitar a natureza, nas formas e nas informações que dela podemos retirar. Educar era “[...] providenciar para que os espíritos dos jovens sejam preservados das corruptelas do mundo e para que as sementes de honestidade neles lançadas sejam, por meio da admoestação e exemplos castos e contínuos" (Comenius, 2001, p. 39). Desse modo, o processo educacional não estava ligado apenas a uma formação intelectual ou moral, mas

Educação \& Realidade, Porto Alegre, v. 40, n. 4, p. 1169-1189, out./dez. 2015.

1171 
também tratava da formação de um homem que se conformasse com os preceitos de sua sociedade e que contribuísse para sua manutenção.

As contribuições de Comenius, considerado o pai da Didática, denotam o valor da educação para o momento histórico e o local onde ele vivia. Sua obra foi esquecida por dois séculos e somente no século XIX seu tratado da arte universal de ensinar tudo a todos ficou conhecido na Europa e disponibilizado para outros países, tornando-se um clássico do pensamento pedagógico da escola moderna. Ele comparava a atitude do mestre com a do jardineiro. Para ensinar, era necessário que o mestre reconhecesse as necessidades e possibilidades de seus discípulos como o jardineiro reconhecia as demandas e as virtudes de suas plantas. Formado pelo pensamento cristão, Comenius vislumbrava a Educação como uma jornada que ensina o homem a ser senhor de si mesmo e que, mesmo diante dos pecados da vida, ser educado era uma forma de saber os caminhos para Deus (Suchodolsky, 1978; Comenius, 2001).

No século XVIII, a Educação também foi uma preocupação de John Locke (1999) na formação moral e para isso, desde a infância, era preciso submeter a criança às normas da boa educação. Diz o autor: “[...] fazei poucas leis, mas cuidai que uma vez feitas, sejam rigorosamente observadas [...] à medida que a idade dele aumente, quando uma regra estiver bem estabelecida pela prática, podereis acrescentar outra" (Locke, 1999, p. 162). No pensamento desse intelectual é que a criança, vista então como uma tábula rasa, precisava ser marcada com o conhecimento, e a Educação seria esse processo de impressão das marcas da sociedade e da cultura na constituição moral e intelectual da criança.

A disciplina na modernidade ${ }^{1}$ é um elemento essencial para a formação do cidadão e do homem almejado para a Europa. Entre os filósofos e intelectuais que versaram sobre educação, Immanuel Kant (1996) argumenta que a disciplina é um componente imprescindível para a aprendizagem da criança. Suchodolsky (1978) explicita que, para Kant, como o conhecimento e a conduta eram criações humanas, fazia-se necessário impor a cada indivíduo os valores e os deveres.

Desse modo, a "disciplina transforma a animalidade em humanidade" (Kant, 1996, p. 11), passando da negatividade para a positividade da educação. No início, a criança deveria ir à escola não para aprender, mas para desaprender, para ser purificado das manhas e das vontades sempre sanadas pelos pais. Depois de disciplinado, aprendendo a ficar sentado, a obedecer às regras da sala, o aluno estava pronto para a positividade da educação, para receber os conteúdos desenvolvidos, para se tornar um homem de bem e, no caso de Kant, um homem moral, cidadão e conhecedor do mundo.

Suchodolsky (1978) explica que John Herbart foi um dos intelectuais inspirados nos estudos e discussões de Kant (1996) para pensar sua proposta de ensino. Os passos pedagógicos delineados por Herbart

1172 Educação \& Realidade, Porto Alegre, v. 40, n. 4, p. 1169-1189, out./dez. 2015. 
- preparação, apresentação, associação, generalização e aplicação denotam as características necessárias para a prática dos mestres no ato de ensinar. $\mathrm{O}$ mestre deveria cumprir com essas etapas para levar a criança da ignorância ao conhecimento (Ghiraldelli, 2000).

A Didática de Herbart está em consonância com a perspectiva tradicional de escola e tinha características como: o conhecimento é centrado no mestre, o aluno é entendido como um aprendiz que deveria manter-se em silêncio e o método é baseado no decorar. O intuito de ensinar o aluno era que ele adquirisse por meio da repetição dos conhecimentos que eram, na perspectiva desses pensadores, necessários para se viver em seus tempos e nas localidades que residiam. Destacamos que o tempo e o espaço para esses pensadores eram referenciados, medidos e organizados com base nos eventos da natureza, nos animais e nos processos científicos.

Alterações nesse pensamento ocorreram no final do século XIX até primeira metade do século XX, com a disseminação das ideias de John Dewey (1975), que escreveu sobre Educação no contexto do desenvolvimento industrial econômico capitalista estadunidense. Nessa perspectiva, ensinar a criança era relacionar as experiências e vivências no processo de aprendizagem. O pedagogo procura trabalhar a relação entre interesse e esforço e o/a professor/a é o responsável por incitar interesse e alimentar o esforço do/a aluno/a em aprender a resolver problemas. A noção de espaço e tempo é importante para o entendimento da pedagogia da Escola Nova ${ }^{2}$. Dewey $(1975$, p. 113) explica que “[...] o problema de educadores, mestres, pais e do próprio Estado, em matéria de Educação, é fornecer ambiente no qual as atividades educativas se possam desenvolver". O pedagogo ainda reitera que ao fornecermos elementos e materiais para incitarmos o interesse da criança, as experiências vividas farão com que o conhecimento tanto intelectual quanto social seja construído no processo de aprender pela vida.

A dicotomia entre as pedagogias da essência e da existência perpassaram toda a História da Educação. Nas últimas décadas do século XX, Suchodolsky (1978, p. 118) defendeu a necessidade da relação dialética entre didáticas que estimulem a formação de outra sociedade em que a atividade pedagógica e a atividade social contribuam para tornar o/a aluno/a criativo/a, a fim de desenvolver a transformação da realidade futura.

A Didática constituída nos movimentos discutidos por Suchodolsky (1978) entre essência e existência ${ }^{3}$ faz-se presente na educação contemporânea. Desse modo, ancorados nas problemáticas sobre a vida não-fascista apresentada por Foucault (1988), recorremos à noção de modernidade e metanarrativa discutidas por Silva (1994), Macedo (2010) e Veiga-Neto (2003) e as análises da mídia e da contemporaneidade de Canclini (2007) e Sibilia (2012) para pensarmos a relação entre formação docente e Didática.

Educação \& Realidade, Porto Alegre, v. 40, n. 4, p. 1169-1189, out./dez. 2015. 


\section{Didática na Contemporaneidade: a contribuição das mídias}

No texto Introdução a vida não-fascista, Foucault (1991, p. 1) explica que entre os anos de 1945 e 1965, “[...] havia uma maneira correta de pensar, um certo estilo político, uma certa ética do intelectual” que explicitavam as questões econômicas, sociais, culturais, psicológicas e ambientais. "Era preciso estar na intimidade com Marx, não deixar seus sonhos vagabundearem muito longe de Freud, e tratar os sistemas dos signos - o significante - com o maior respeito". Ao apontar essas perspectivas, o autor explica que falar a verdade sobre si, pelo menos uma parte dependia dessas vertentes anteriores.

Foucault (2009, p. 44) contribui para esta análise ao explicitar que a educação “[...] é uma maneira política de manter ou de modicar a apropriação dos discursos, com os saberes e os poderes que trazem consigo". O autor entende o ensino como um rito que envolve o significado das palavras, a estabilidade organizada das posições dos sujeitos, a construção de doutrinas e a distribuição de discursos forjados nas relações de saber-poder. Nesta análise, a prática educacional moderna está comprometida com o "[...] adestramento do corpo, do comportamento, das aptidões engendram o problema daqueles que escapam dessa normatividade" (Foucault, 1997, p. 63). É uma forma de regular e normalizar os sujeitos.

As contribuições deste intelectual francês são para o reconhecimento do papel do discurso. Para ele, as práticas discursivas são como lentes, pois, em cada momento histórico “[...] os homens perceberam todas as coisas, pensaram e agiram; elas se impõem tanto aos dominantes quanto aos dominados, não são mentiras inventadas pelos primeiros para dominar os últimos e justificar sua dominação" (Veyne, 2011, p. 51). A compreensão dos estudos de Foucault constitui olhares para os discursos que consolidaram a Didática e a Educação.

A aproximação dos ensinamentos do intelectual com o campo educacional pode ser vislumbrada em pesquisas que foram desenvolvidas também por Alfredo Veiga-Neto (2007).

[...] Foucault vai muito além daqueles que, no campo pedagógico, costumam simplificar e dividir o mundo dos discursos em dois blocos: de um lado, o bloco dos discursos admitidos e, de outro, o dos discursos excluídos; ou, num outro recorte, o bloco dos discursos dominantes e o dos discursos dominados; ou, num outro recorte ainda, o bloco dos discursos do poder e o dos discursos da resistência. Essas são oposições que, de fato, convidam a um tratamento dialético...E é sempre isso que acontece na maioria dos estudos que se fazem no Brasil, no campo da Educação. Mas, na perspectiva foucaultiana não há lugar para isso; não se trata de dialetizar o mundo...Em vez de

1174 Educação \& Realidade, Porto Alegre, v. 40, n. 4, p. 1169-1189, out./dez. 2015. 
entender que existem tais blocos antagônicos e se procuram contrapô-los, talvez seja mais interessante e produtivo, em termos tanto teóricos quanto políticos, perguntar pelos processos que estabelecem uma verdade, pois é aí que se dão a arbitrariedade e a violência da exclusão, e não propriamente dentro de um discurso, nas proposições em si (Foucault, 1996). Isso significa empreender um escrutínio e problematizar em torno dos regimes de verdade, e não propriamente por dentro deles (Veiga-Neto, 2007, p. 103-104).

O pensamento educacional teve contribuições dessas teorias que foram sublinhadas por Foucault (1991) e, até hoje, o campo educacional ainda traz marcas desta visão de sociedade, sujeito e cultura. Silva (1994) entende que as teorias educacionais e a pedagogia estão sob ataques impiedosos das vertentes que repensam a ciência e a Educação, retirando o lastro iluminista de produzir sentidos por meio de aspectos modernizantes para pensarmos a encruzilhada social e cultural que temos na contemporaneidade.

Assumirmos a percepção da História acerca dos eventos educacionais e culturais é, também, reconhecer os riscos e as perturbações que sentimos como efeitos do processo de formação. Negar a ideia de essência da Educação, dos sujeitos e das sociedades é no curso da movimentação enxergar os desmoronamentos e as aberturas, treinando o olhar para encontrar caminhos entre as ruínas dos projetos de sociedade e educação modernos (Sibilia, 2012).

Para Foucault (1987), a educação na instituição escolar é um adestramento de corpos. A sociedade disciplinar, diferentemente da proposta de uma formação humana para problematizar os modos como vivemos, formata corpos e subjetividades nos postulados de verdade e normalidade. Estigmatizados, os sujeitos que não pertencem aos critérios centrais da noção de homem discutida por Macedo (2010), como homem branco, heterossexual e cristão, eram expurgados, ou mesmo serviam de exemplo a não ser seguido. O cuidado de si como técnica da existência e formação ética "[...] não se trata, simplesmente, de formar para o futuro um homem de valor. É preciso dar ao indivíduo as armas e a coragem que lhe permitirão lutar durante toda a sua vida" (Foucault, 1997, p. 124).

Retomamos a relação feita por Foucault (1997) como a cuidado de si para pensarmos o viés regulador/produtivo da educação. No campo do ensino e aprendizagem, a abordagem culturalista fornece perspectivas para as análises dos aspectos produtivos do poder.

O que distingue a posição pós-estruturalista, nisso baseada novamente em Foucault, é a ênfase no caráter necessário e produtivo do poder. Enquanto para a teorização crítica de inspiração marxista, por exemplo, o poder distorce, reprime, mistifica, para a perspectiva pós-estruturalista,

Educação \& Realidade, Porto Alegre, v. 40, n. 4, p. 1169-1189, out./dez. 2015. 
o poder constitui, produz, cria identidades e subjetividades. As identidades e subjetividades assim produzidas não representam nenhuma distorção, nenhum desvio em relação a alguma essência humana que, se deixada livre ou 'bem' encaminhada, seguiria o seu 'verdadeiro' curso (Silva, 1994, p. 252).

A Didática, desse modo, como disciplina do curso de Pedagogia e das licenciaturas que constituem o acervo de conhecimentos da escola, é um eixo de pesquisa. A ação docente na Educação Básica, se nos referenciarmos pelas contribuições de Foucault (1997), não precisa cumprir com uma função coercitiva de formação. A Educação passou por diferentes momentos, ora como salvadora da sociedade, ora como vilã corrupta de costumes. Silva (1994, p. 254) nos alerta que abandonar os significados transcendentais "[...] - como o das metanarrativas - não deve deixar saudades”. Se podemos abandonar as verdades fundantes para pensar as possibilidades de ser, pensar e agir, nossa didática pode acompanhar, ser produzida e constituir-se neste processo formativo.

A perspectiva desconstrucionista ${ }^{4}$ propõe análises acerca do caráter produtivo de significações, processos e culturas. Ao pensarmos em uma prática de cuidado de si (Foucault, 1997), em uma sociedade que reconfigura as práticas e os processos (Macedo, 2010), a educação que abandona as metanarrativas (Silva, 1994), a Didática ganha outros contornos, atuações, pensamentos e desejos. Preferir “[...] o que é positivo e múltiplo, a diferença à uniformidade, os fluxos a unidades, os agenciamentos móveis aos sistemas, considere que o que é produtivo não é sedentário, mas nômade" (Foucault, 1991, p. 2). Desse modo, olhar para a Educação e o processo de formação na contemporaneidade é vislumbrar potenciais para uma Didática diferente e que repense o fazer docente, a rigidez e a experiência.

A educação é "um campo minado de metanarrativas” (Silva, 1994, p. 256) e a Didática - assim como outras disciplinas e práticas docentes - foram constituídas e dogmatizadas na busca por uma formação que respondesse às expectativas de um projeto moderno ${ }^{5}$. Golpear as certezas e atirar-se "[...] contra o edifício teórico educacional, seja aquele tradicionalmente construído, seja o da teorização crítica” é um dos conselhos de Silva (1994, p. 256). Por que estamos abandonando essas perspectivas encarceradoras da educação?

Canclini (2007, p. 35) responde que “[...] há décadas, aqueles que estudam a cultura experimentam a vertigem das imprecisões”. Desse modo, a didática é um campo, uma perspectiva, uma lente teórico-metodológica para pensar a nossa sociedade e a educação como eixo que estrutura os modos de pensar, ser e agir. Didática é um conjunto de atos comunicacionais, históricos, sociais, políticos e econômicos. Pensar a didática é preocupar-se como um educando que testemunha e produz seus atos sociais.

1176 Educação \& Realidade, Porto Alegre, v. 40, n. 4, p. 1169-1189, out./dez. 2015. 
Os conhecimentos acerca da didática são reverberados como receitas prontas. Materiais didáticos, lista de tarefas a serem executadas e um excesso de atividades estimulam docentes a buscar por atividades que estejam inseridas na expectativa de ensinar do jeito certo. Não precisamos de receitas prontas, porque são essas certezas que podem ser questionadas. Não temos apenas uma forma de aprender e ensinar no espaço da sala de aula, que é ocupado por diferentes culturas, identidades e desejos. A ciência, mesmo com seu status de discurso próximo a verdade, é reconhecida como plural e os objetos por ela analisados são provisórios, parciais e são permeados por muitas possibilidades (Canclini, 2007).

Desorganizados, os sujeitos da educação precisam de outras perspectivas, de diferentes valores, circunstâncias, projetos e interesses que interajam com a ideia de formação e produção de conhecimento como instável, plural e provisória. Assim, “[...] os dispositivos eletrônicos que convivemos e que usamos para realizar as mais diversas tarefas com crescente familiaridade e proveito, desempenham um papel vital nessa metamorfose" (Sibilia, 2012, p. 51). O uso de tecnologias e a releitura de vivências e experiências com base nesses artefatos culturais também denotam a instabilidade e as alterações "[...] gerando maneiras inéditas de ser e estar no mundo” (Sibilia, 2012, p. 51).

Nascidos e criados entre as mídias interativas como cinemas 3D, jogos eletrônicos, celulares com acesso à $w e b$, crianças e adolescentes - alunos/as nas etapas da educação básica e do ensino superior - vivenciam e experimentam o conhecimento, a informação, o espetáculo e as relações se constituindo de modos diferentes. O rigor, o funcionamento analógico de instrumentos como quadro de giz, os regulamentos, os boletins, horários, carteiras alinhadas, uniformes, provas e avaliações compõem um cenário desinteressante para os/as educandos/as porque estão acostumados com um fluxo ininterrupto de informações descartáveis. Desse modo, o movimento didático formativo de um tema trabalhado por alguns minutos é exaustivo (Sibilia, 2012).

A formação docente e, em nosso foco de estudo, o ensino da didática tem fascínio pelas respostas prontas, pelas estratégias que prometem entreter as crianças de tal maneira que fiquem atentas em todo momento no processo educacional. Mesmo com a análise feita por Sibilia (2012) em que a escola parece desinteressante aos/às alunos/as por causa de outros estímulos oriundos das mídias ou outros espaços sociais, a vontade de ensinar de forma fascinante o aprendiz, bem como a necessidade de uma maneira correta de educar são delineamentos do que denominamos didática fascista. Além do “[...] fascismo histórico de Hitler e Mussolini - que soube tão bem mobilizar e utilizar o desejo das massas" existe “[...] também o fascismo que está em todos nós, que assombra nossos espíritos e condutas cotidianas, o fascismo que nos faz amar o poder, desejar esta coisa mesma que nos domina e nos explora" (Foucault, 1991, p. 1-2). 
A sensação de ser dominado e subjugado faz-se presente durante o processo educacional. Nas análises sobre as relações de poder, Foucault (1987) trata do caráter de docilização dos corpos da instituição escolar. A didática é um dos saberes dessa engenharia, como fetiche ou um objeto de feitiço, que seduz e leva os sujeitos a crerem em um potencial sagrado do conhecimento dessas estratégias. Esse conhecimento de como ensinar seduz professores/as e convence que saber seus postulados, aliados às metodologias de ensino e às práticas pedagógicas, são os saberes necessários para se exercer o poder, adestrar e amansar alunos/as.

Ao tratarmos da didática fascista, não buscamos uma resposta específica a esta questão de poder, de desejar o domínio sobre os saberes de como conduzir o ensino. Estamos atentos aos fascismos possíveis no processo educacional, entretanto, e vislumbramos outros processos educacionais possíveis para além do desejo de dominar e subjugar pelo conhecimento. As sensações pós-modernas ${ }^{6}$ que permeiam os processos sociais e educacionais, que liquefazem as certezas também modificam o funcionamento de uma maquinaria escolar.

Sobre o fascismo como desejo pelo poder, Reich (1988, p. 13-14) escreve que o fascismo só poderá ser vencido por meio de "[...] um conhecimento bem fundado dos processos da vida". O autor explica que "[...] o fascismo não tem resposta para os problemas práticos da vida porque vê tudo apenas como reflexo da ideologia ou sob a forma dos uniformes oficiais". Em sua análise, a mentalidade fascista está no desejo de poder do sujeito comum revoltado e cansado de ser subjugado e precisa conquistar adeptos para alcançar autoridade reconhecida. Na posição de comando, escolhe os inimigos e fundamenta sua particularidade no orgulho, na vontade de poder e na necessidade que o sujeito sente em vencer a exploração.

A didática fascista também se vale desse desejo de poder. Menos do que dominar os sujeitos por preceitos de pureza ou de manobrar uma massa para confiar nas respostas que emergem em momentos de crise, essa didática se coloca como resposta aos problemas da educação. Insere o discurso de que ensinar está relacionado apenas com as qualidades de professor/a e negligencia toda a estrutura educacional, as múltiplas narrativas e os possíveis discursos em uma sala de aula. Buscar ensinar tudo a todos, uma das premissas dos conhecimentos educacionais do período moderno, também está em questão. Qual seria a possibilidade de pensar a didática em outro contexto? Desfazer-se da ilusão do poder seria possível? Foucault (1997) destaca as relações de poder não apenas como opressivas e coercitivas, mas também o poder como produtivo. E, desse modo, uma didática não-fascista se inscreve nas possibilidades de pensarmos como sujeitos de um cuidado de si. Nossa aposta intelectual e teórica é que no processo de conhecer a si, de perceber-se e localizar-se, mesmo que de forma provisória e fragmentada, oferece-nos condições para perceber as lógicas oferecidas pela didática fascista. Ao 
interpretarmos o mundo por nossas subjetividades, nossas condicionantes históricas, nossas práticas científicas, não separadas ou organizadas em fases, mas múltiplas, caleidoscópicas, a didática não-fascista torna-se possível por envolver-se com o aprender de alunos/as antes de um ensinar tudo a todos como é a promessa da didática fascista. Nessa perspectiva, a palavra todos não inclui as minorias sociais, culturais, econômicas, políticas e identitárias. Do mesmo modo, esse tudo ressaltado pela perspectiva didática é apenas o que foi produzido dentro de uma ideia de cultura como máxima elaboração humana, esvaziada das potencialidades do eu em fazer-se no seu processo educacional como uma obra de arte, tal como nos ensina Foucault ${ }^{7}$ (2014).

\section{Educação e a Pedagogia do Conflito}

A escola foi produtora de desigualdades desde sua fundação. Seu caráter instituidor e normativo definia-se pela separação entre quem poderia aprender e quem estava aquém do projeto de modernidade. Construída para receber uma parcela de crianças para aprender o que se julgava importante no conhecimento moderno, a instituição baseou-se em “[...] organização, currículos, prédios, docentes, regulamentos, avaliações” que tinham por objetivo “[...] 'garantir' - e também produzir - as diferenças entre os sujeitos” (Louro, 1997, p. 57).

Os conhecimentos, os sujeitos, as práticas e as normas estabelecidas construíram gestos, movimentos, sentidos que instauraram e fazem a manutenção de corpos, práticas e desejos. Os sujeitos da educação mudaram com a difusão de tecnologias e a escola ainda mantém seu status de constituidora do ideal de sociedade moderna. Skliar (2003, p. 39) argumenta que a diversidade de sujeitos "[...] apenas se nota, apenas se entende, apenas se sente", entretanto, compreender o outro não se tornou ainda uma prática da escola e, desse modo, também não tem sido pertinente para alimentar as leituras e as análises para pensarmos as didáticas.

O outro ainda está “[...] massacrado, assimilado, ignorado, excluído e incluído, e, por isso, para negar nossa invenção do outro preferimos afirmar que estamos frente a frente com um novo sujeito" (Skliar, 2003, p. 39). Com a entrada da diferença na educação formal, as múltiplas identidades causaram estranhamento, fragilizaram os projetos homogeneizadores, enfraqueceram a noção de condução da educação e causaram mais dúvidas.

Um tempo presente que permita nos desvanecer para criar uma outra pedagogia. Uma pedagogia do acontecimento, uma pedagogia descontínua, que provoque o pensamento, que retire do espaço e do tempo todo saber já disponível; que obrigue a recomeçar do zero, que faça da mesmidade um pensamento insuficiente para dizer, sentir, compreender aquilo que tenha acontecido; que emu-

Educação \& Realidade, Porto Alegre, v. 40, n. 4, p. 1169-1189, out./dez. 2015. 1179 
deça a mesmidade. Que desordene a ordem, a coerência, toda pretensão de significados. Que possibilite a vaguidade, a multiplicação de todas as palavras, a pluralidade de todo o outro. Que desminta um passado unicamente nostálgico, somente utópico, absurdamente elegíaco. Que conduza a um futuro incerto (Skliar, 2003, p. 46).

Ter o outro como foco do olhar pedagógico é uma busca por pensar sobre a constituição das identidades e das subjetividades e como os discursos constituem as noções de identidade e diferença nas práticas educacionais. Se antes, “[...] está mal ser o que és” e “[...] está bem ser alguma coisa que nunca poderás ser” (Skliar, 2003, p. 46). Santos (1996) trata da sensação de incômodo que vivemos no contemporâneo e, que nos ajuda de modo profícuo a pensar em uma didática não-fascista. As verdades que sustentavam as atividades educacionais, o ensino como prática que leva o conhecimento para os/as alunos/a são revistos nesse momento de sensações pós-modernas. A didática também é pensada neste contexto. Os métodos de ensino, as funções do/a professor/a são revistas entre as teorias pedagógicas, e denotam o que o autor denomina da sensação de estarmos parados, que incomoda pesquisadores/ as, professores/as e alunos/as. As mídias sugerem movimento e os/as alunos/as não ficam parados/as. Essas crises nos apresentam as sensações pós-modernas e visibilizam as necessidades contemporâneas em repensar práticas educacionais e os sujeitos culturais envolvidos no processo de aprendizagem.

O movimento e o projeto educativo que se delineia em sensações pós-modernas está na prática de reconhecimento das fragilidades, das identidades, dos processos de negociação que denotam que o pensar-se está imerso em relações da educação e da cultura. "O sofrimento humano mediatizado pela sociedade da informação está transformando numa telenovela interminável em que as cenas dos próximos capítulos são sempre diferentes e sempre iguais às cenas dos capítulos anteriores" (Santos, 1996, p. 16-17). O estímulo para identificar-se, para entrar em contato consigo, está relacionado aos padrões e as normas instituídas pelo projeto moderno. Escola e mídia como instituições instauradas no plano cartesiano de progressão em busca da verdade podem ser questionadas para pensamos as possibilidades de ver a Educação por outras perspectivas.

A educação para o inconformismo tem de ser ela própria inconformista. A aprendizagem da conflitualidade dos conhecimentos tem de ser ela própria conflitual. Por isso, a sala de aula tem de transformar-se ela própria em campo de possibilidades de conhecimento dentro do qual há que optar. Optam os alunos tanto quanto os professores e as opções de uns e outros não têm de coincidir nem são irreversíveis. As opções não assentam exclusivamente em ideias já que as ideias deixaram de ser desestabilizadoras no nosso tempo. Assentam igualmente em emoções, sen-

1180 Educação \& Realidade, Porto Alegre, v. 40, n. 4, p. 1169-1189, out./dez. 2015. 
timentos e paixões que conferem aos conteúdos curriculares sentidos inesgotáveis. Só assim é possível produzir imagens desestabilizadoras que alimentem o inconformismo perante um presente que se repete, repetindo as opções indesculpáveis do passado. O objetivo último de uma educação transformadora é transformar a educação, convertendo-a no processo de aquisição daquilo que se aprende, mas não se ensina, o senso comum (Santos, 1996, p. 18).

Nesses conflitos percebemos a aplicação de conhecimentos e a prática da aprendizagem como um possível modo de aprender sobre si. É necessário o desenvolvimento de olhares exóticos8. Desse modo, não é apenas um movimento de olhar para resultados, mas pensar nos processos de aprendizagem; é a perspectiva de constituir entre os olhares técnicos e éticos, pensar nos olhares locais e globais que constituem nossos modos de pensar a sociedade, as práticas e as políticas que envolvem a educação. Reconhecer os olhares locais, as particularidades e relacionar suas aplicabilidades à visão geral; ter fechado o horizonte contabilístico evidencia os fins e ressalta os meios disponíveis (Santos, 1996).

As dificuldades de uma troca entre culturas que não seja desigual e o projeto político emancipatório são oportunidade para pensarmos em uma didática não-fascista. A pedagogia do conflito discutida por Santos (1996, p. 32) contribui para a desestabilização de modelos dominantes, para relacionamentos mais igualitários e "[...] que nos faça aprender o mundo de modo edificante, emancipatório e multicultural. Será este o critério último da boa e da má aprendizagem”. Desse modo, a didática não fascista vincula-se a uma prática de conhecer-se e constituir-se como sujeito dos múltiplos processos da aprendizagem.

Assim, com base nos contextos contemporâneos, vislumbramos as mídias como dispositivos que estimulam os múltiplos discursos, o diálogo e a possibilidade de troca de informações e pontos de vista. Uma didática não-fascista está envolvida com a aprendizagem pela experiência, com o reconhecimento dos múltiplos e das possibilidades, ou, como destaca Foucault (1991), por meio das possibilidades militantes, que não sendo fáceis, também não são desestimulantes para a prática social e que podem ser fecundos para a atuação docente. A experiência da construção de sentidos e significados nas atuações localiza mesmo que provisoriamente alunos/as e professores/as em suas condicionantes históricas, práticas intelectuais e processos culturais que forjam nossos modos de ver, pensar e interpretar o mundo.

\section{Releituras da Didática}

Estimulados/as pela performance, pelos modos de ser e estar no mundo e pelas práticas que constituem os gostos, os grupos, as redes 
de relações por meio das experiências nas redes sociais, alunos/as, professores/as e outros sujeitos da educação elencam assuntos e prioridades, até então, desligadas do espaço escolar pelo pretexto de não serem conteúdos historicamente acumulados pela humanidade. O corpo, as artes, o sexo, as práticas de convivência e o desejo de olhar para si mesmo, refratados pelas mídias nos fornecem outros elementos e critérios para as análises. Leitura e escrita foram vinculadas como processos de expressão, modos de vivenciar quem somos e como pensamos o mundo. Artesanal, o processo de pensar-se é também um processo didático que se faz necessário para a formação docente. A didática não fascista vale-se desse processo de conhecer-se, pouco a pouco, dos elementos que nos constituem as práticas que produzimos e que nos produzem para pensar o exercício da educação como um ensinar-se a si sobre si mesmo e ensinar aos outros o processo provisório que é encontrar-se em aprendizagem.

Foucault (1991, p. 2) explica que o pensamento não deveria ser utilizado para "[...] dar a prática política um valor de verdade". A política como prática seria um modo de intensificar o pensamento, produzir análises como multiplicações de formar o desejo pelas intervenções políticas. "O indivíduo é o produto do poder", afirma o autor. Na contemporaneidade, vislumbrar a didática é percebê-la como eixo da produção. O poder e o saber das relações de ensino e aprendizagem constituem indivíduos, identidades, sujeitos, práticas e processos. A didática está relacionada ao pessoal, mas também ao grupo, às necessidades sociais, culturais, políticas e econômicas que sugerem práticas de atuação.

Sibilia (2012, p. 78) explicita que a entrada em uma instituição de ensino e uma recepção aos/às alunos/as é a vivência de um choque. A crise se instala porque diferente das outras instituições sociais como a família, a religião, as mídias, a escola mantém as engrenagens e os processos do mesmo modo que foi pensada em sua constituição. Para a autora, a instituição escolar/educacional não consegue mais produzir "[...] uma subjetividade capaz de habitá-las".

Os acessos a diferentes conteúdos e informações não dependem mais da escola para ocorrerem. Sennett (1999) explica que as noções de segurança e de certeza tão caras à modernidade, hoje são vistas como enfadonhas e frágeis. O incerto, a dúvida e a mudança são as prerrogativas para uma vida contemporânea. O que antes era ensinado e aprendido nas escolas, hoje também são conhecimentos dispersos em sites, blogs e outros repositórios de informação das redes da internet. O/A professor/a em sua didática precisa atentar para essa disponibilidade de conteúdos e, desse modo, uma didática não-fascista é feita na relação entre professores/as e alunos/as, construída nas relações de aprendizagem, nos diferentes discursos que tecem as experiências dos sujeitos que estão envolvidos no processo didático.

Sujeitos fluidos e extremamente rápidos, os/as alunos/as das instituições educacionais contemporâneas reestruturam a linguagem, as 
imagens, os sentidos e as expressões. Quando eles/elas estão interessados/as pelo novo, pela mudança e pela dinamicidade, o espaço escolar é visto como um espaço físico de aprendizagem e convivência. Os celulares, entretanto, permanecem conectados às redes sociais e recebem atualizações permanentemente. Fotos, textos, frases de diferentes autores, trechos de música, vídeos, entre outras produções próprias ou compartilhadas são conteúdos que dividem o tempo dos/as alunos/as entre as tarefas e os afazeres escolares, a vida social e o desejo de comunicar tudo a todo o momento (Sibilia, 2012).

Vislumbramos outras performances. Não apenas receptores ou mesmo interlocutores, mas também produtores e difusores de interpretações, análises e informações, alunos/as aprendem nas experiências midiáticas, conhecem diferentes culinárias, buscam informações de lugares, visualizam diferentes práticas sociais, entram em contato com múltiplas experiências que parecem mais fascinantes e úteis que os conhecimentos transmitidos no espaço escolar.

E como pensar a didática com o desestimulante número de publicações em redes sociais que maldizem as segundas-feiras e louvam os finais de semana? Não encarando o processo de produção e relação com as mídias como um problema, a prática didática necessita dessas relações para pensar a educação contemporânea. Para usar as mídias nos processos educacionais, Teruya (2006, p. 102) destaca que é importante os/as professores/as estimularem “[...] o[/a] aluno[/a] a fazer uma pergunta. Porque, se alguém tem uma pergunta precisa, deve achar a resposta; se não tem, o labirinto [da internet] o coloca em um beco sem saída e o sujeito fica dando voltas em círculo".

Sibilia (2012) explica que estimulados pelo imperativo de diversão, os processos mais lentos, que necessitam de atenção e demandam um processo contínuo de relações e construções sistemáticas, são encarados pelos/as alunos/as como enfadonhos. A didática que se constitui na busca por uma pergunta, por constituir um objetivo a ser conquistado, a necessidade de resposta, mesmo que provisória, contribui para que alunos/as olhem com atenção as demandas sociais, culturais, econômicas e políticas. Uma didática que oportuniza a observação e a análise precisa ser pensada na formação docente que pense a educação básica hoje como possibilidade formativa, como território de constituição das diferentes identidades que estão no espaço escolar e dos discursos que as permeiam.

Foucault (1991, p. 2) traz a problemática do movimento de militância para pensar a possibilidade de resistência ao afirmar que "[...] não imagine que precise ser triste para ser militante”. A expressão de luta que permite repensar as verdades estabelecidas aproxima-se do conselho do autor para que não nos apaixonemos pelo poder. O poder/saber na constituição do campo de atuação e prática docente tem sido usado como justificativa de construção de certezas. Abrir mão das certezas, para, com o olhar das relações entre saber/poder pensarmos

Educação \& Realidade, Porto Alegre, v. 40, n. 4, p. 1169-1189, out./dez. 2015.1183 
nossas atuações, é uma forma de dialogar com a problematização da didática.

Reconhecer o aspecto relacional do espaço escolar, bem como as condições de uma educação como processo, não como certezas justificadas por um projeto de ciência, poder ou política é desencantar-se com o poder, é abrir mão de determinadas hierarquias e reintegrar os olhares. Durante muito tempo, como explica Louro (1997), a escola separou o que era dela e o que nela entrava, do que era abjeto ou mesmo inútil segundo os critérios de saber e verdade instituídos pela escola na modernidade.

Romper com o projeto de uma arte de ensinar tudo a todos e reconhecer a relação Eu-Outro no processo educacional é um modo de pensar a pergunta que "[...] pode ser também um abandono, um nevoeiro ou um cruel convite à sinceridade” (Skliar, 2003, p. 39). Este autor nos instiga a pensar a educação e nós, como sujeitos constituídos e constituidores deste processo, de aprender e ensinar. Atentos à didática, não vemos um processo utilitarista como um fim a ensinar de um modo estático, rígido e correto de pensar, mas aceitamos o convite de Foucault (1991, p. 2) por uma "[...] caça a todas as formas de fascismo, desde aquelas, colossais, que nos circundam e nos comprimem, até as formas pequenas que fazem a amarga tirania de nossas vidas cotidianas".

E como pensamos a escola e a didática nesses contextos? Sibilia (2012) nos adverte sobre o desafio de lidar com o excesso de informações e estímulos "gerando subjetividade e encontros" que causa uma "saturação total" e "nos impede de pensar e de agir" na atuação docente que não foge a essas relações (Sibilia, 2012, p. 92). A lentidão do processo educacional e a complexidade dos conteúdos desestimulam alunos/as e professores/as a pensarem em estratégias que revigorem a prática e pensem a relação.

Ao discutir sobre uma pedagogia do conflito, Santos (1996) trata da necessidade de desestabilizar certezas e repensar a prática docente. É com base nesse incômodo causado pelo autor e nas discussões feitas sobre uma vida não-fascista descrita por Foucault (1991), que pensamos uma didática na educação básica. As discussões que traçamos neste texto não pretendem formular uma resposta redentora de como a didática deve ser pensada, de que saberes e poderes são válidos para ensinar. A didática não-fascista, em nossa perspectiva, é uma oportunidade de reconhecer o campo educacional como um campo de subjetividades em processo. Uma didática contra o fascismo é, desse modo, uma possibilidade para pensar uma educação plural, múltipla e incerta. Um processo que não começa ou acaba, mas abre-se para pensar a história, a cultura e a política que envolvem a educação.

1184 Educação \& Realidade, Porto Alegre, v. 40, n. 4, p. 1169-1189, out./dez. 2015. 


\section{Considerações Finais}

Não defendemos a didática como um receituário e nem certezas ao expressarmos quando pensamos na formação de professores/as nas diferentes licenciaturas. Os/As professores/as em formação precisam pensar sobre como a aprendizagem está relacionada com as liberdades e as regulações do processo educacional. Ignorar os pressupostos didáticos apresentados por outros autores, desde a formulação do campo da didática até as contribuições recentes, é esquecer a necessidade de reconhecer a construção histórica, social, cultural e política da educação. Não é este nosso objetivo.

Buscamos com este texto elucidar a necessidade de reconhecer a histórica luta para a constituição do campo educacional, as contribuições e as discussões teórico-metodológicas da educação. Uma didática não-fascista se faz necessária para abrirmos mão das certezas e receitas prontas e estudar, ler, pensar e abandonar nossas necessidades de certezas que contribuem para refazer o caminho até a sala de aula. Reconhecer a disciplina de Didática como espaço para olhar a educação básica é uma das formas de alimentar as dúvidas, as incertezas e os desconfortos. É em busca de uma pedagogia do conflito para atender as necessidades de uma sociedade permeada pelas mídias que uma didática não-fascista se faz possível.

Para constituir-se, esta didática depende do processo experiencial das relações do sujeito com o mundo. Perceber-se como constituído e constituidor de sentidos, faz do/a docente e do/a aluno/a sujeitos que dividem a tarefa de localizarem-se na aprendizagem como companheiros no processo de conhecer o mundo, mesmo que provisoriamente. Essa experiência pode ser enriquecedora. Entretanto, é necessário que os sujeitos da educação reconheçam o conhecer-se como uma prática de si e, ao mesmo tempo, como um processo que instaura formas de agir e de ser.

Vislumbrar-se no processo é perceber as ligações, as relações, os sentimentos, as práticas culturais e os desejos que nos envolvem no conhecimento e na aprendizagem dos conceitos e do mundo. Subjetivar para reconhecer-se, objetivar para dividir e voltar a subjetivar para entender-se - e ver o conteúdo - como um porto provisório, é um momento de constituição para as desconstruções necessárias no desenvolvimento da aprendizagem. Uma didática não-fascista está comprometida, antes de tudo, com o sujeito da aprendizagem, a experiência que forma os sentidos e significados, o desejo de aprender envolvido por docentes e discentes para, depois dessa integração e percepção, olhar para os conteúdos do mundo como pontos a serem conhecidos, interpretados, mas não fixados. A condição de aprendizagem é o processo de aceitar-se um sujeito móvel, provisório e possível. Por essa perspectiva, em tempos de sensações pós-modernas, qualquer fixação pode comprometer-se com uma percepção fascista da realidade, porque a estabilidade é um desejo

Educação \& Realidade, Porto Alegre, v. 40, n. 4, p. 1169-1189, out./dez. 2015.1185 
por segurança e, na aprendizagem, quanto mais estável, menor a visibilidade do processo educacional e a potencialidade de perceber-se como constituidor e constituído pelos sentidos do conhecimento adquirido no processo.

Recebido em 30 de março de 2014 Aprovado em 12 de março de 2015

\section{Notas}

1 A modernidade é um período produzido pelo mito do progresso e oferece normatizações ligadas a ideia de humanidade e cultura universais. As narrativas constituídas e constituidoras dessa modernidade afirmam uma separação entre corpo e mente, razão e emoção, ciência e senso comum. Este período tem como discurso de valoração a ciência e a arte. Essas práticas humanas constituíram as significações desse momento histórico que definiram o centro, o incluído, o correto e o erro. A educação, nesta modernidade, seria o processo de ensinar às crianças o que deveriam ser, para a manutenção de uma sociedade progressista e calcada em afirmações científicas (Peters, 2000; Macedo, 2010).

2 Neste artigo, referimos à perspectiva educacional da Escola Nova pensada por John Dewey. No Brasil, as ideias de Dewey chegou no início da década de 1930, com Anísio Teixeira e denotou um enfrentamento à pedagogia tradicional. Com olhares da biologia e da psicologia, a pedagogia escolanovista dá ênfase ao sujeito da aprendizagem e a atividade criadora do/a aluno/a (Behrens, 2005, p. 44).

3 Para Suchodolski (1978), a pedagogia da essência é uma forma de educação em que o sujeito desenvolve aspectos que são 'naturais' e que pertencem ao sujeito. A pedagogia da existência, de outra ordem, entende o sujeito como alguém que é formado nas relações sociais, culturais, políticas e econômicas nas quais está envolvido.

4 Peters (2000, p. 37) afirma que “[...] a arqueologia, a genealogia, a desconstrução, cada um dos quais funciona de acordo com sua própria lógica, mas, considerados em seu conjunto, eles tendem a enfatizar as noções de diferença, de determinação local, de rupturas e descontinuidades históricas, de serialização, de repetição [...]". A perspectiva desconstrucionista tem o intuito de produzir uma posição que se recusa a entender o conhecimento científico como uma metaexplicação. Para Butler (1998, p. 34), a desconstrução “[...] implica somente que suspendemos todos os compromissos com aquilo a que o termo 'o sujeito' se refere, e que examinamos as funções linguísticas a que ele serve na consolidação e ocultamento da autoridade". Desse modo, a desconstrução é uma prática epistemológica que nos oferece a oportunidade de "abrir um termo, como sujeito, a uma reutilização e uma redistribuição que anteriormente não estavam autorizadas".

5 Projeto moderno é uma proposta de constituição do mundo por meio dos discursos científicos. Com base em uma metodologia de análise quantitativa, os dados científicos são elaborados com base em uma lógica cartesiana de constituição de sentidos e explicações sobre o mundo. No enfoque educacional, essa promessa de lógica científica, projeta sentidos e significados como ordem, progresso, instrução para que o sujeito seja apto para o trabalho e para viver de acordo com a normativa moral do período. É um projeto que se sustenta em uma metanarrativa e enrijece as possibilidades da educação (Takara, 2013).

1186 Educação \& Realidade, Porto Alegre, v. 40, n. 4, p. 1169-1189, out./dez. 2015. 
6 Ao buscar, mesmo de forma provisória constituir a noção de sensações pós-modernas, entendemos que "[...] o pós-moderno enquanto condição da cultura nesta era, caracteriza-se exatamente pela incredulidade perante o metadiscurso filosófico-metafísico, com suas pretensões atemporais e universalizantes" (Lyotard, 2004, p. VIII). Assim, as sensações pós-modernas seriam a experiência cibernético-informático e informacional, aliadas as alterações das noções de linguagens, culturas, processos e práticas que “[...] nos ensinam mais sobre a desconfiança das grandes verdades e desenvolver em nossos olhares o questionamento" (Teruya; Takara; Castellar, 2012, p. 5). Perceber-se e localizar-se neste modo de pensar, contextualiza a incerteza como prática para se pensar e se envolver nas problemáticas contemporâneas, nas relações das tecnologias, no saber-poder e nas práticas culturais e educacionais (Foucault, 1997; 2009; Peters, 2000; Lyotard, 2004).

7 Em 1983, Foucault dá entrevista a Stephen Riggins. Ao tratar da noção de ética, o filósofo francês afirma que as "[...] pessoas devem elaborar sua própria ética, tomando como ponto de partida a análise histórica, a análise sociológica ou toda outra análise que podemos lhes fornecer. Não penso que as pessoas que tentam decifrar a verdade devessem fornecer, ao mesmo tempo, no mesmo livro e com a mesma análise, princípios éticos ou conselhos práticos" (Foucault, 2014, p. 205). A compreensão de Foucault é que o sujeito ético é aquele que entende a vida como obra de arte, como uma produção sua acerca das suas relações com o mundo. Uma relação que envolve a racionalidade, mas que não despreza a sensibilidade, a intuição e os sentimentos tal como pressupõe a Modernidade e a ideia de didática fascista. Nessa perspectiva, a sala de aula é um encontro entre sujeitos integrais e não apenas relações entre alunos e docentes no intuito a gerar um conhecimento técnico e científico que será sempre pouco profícuo, porque envolve uma frigidez racional, apenas.

8 Ao termo exótico, referimos ao fora da ótica, como destaca Louro (2002).

\section{Referências}

BEHRENS, Marilda Aparecida. O Paradigma Emergente e a Prática Pedagógica. Petrópolis: Vozes, 2005.

BUTLER, Judith. Fundamentos Contingentes: o feminismo e a questão do 'pós-modernismo'. Cadernos Pagu, Campinas, UNICAMP, v. 2, n. 11, p. 11-42, 1998.

CANCLINI, Néstor García. Diferentes, Desiguais e Desconectados. Rio de Janeiro: UFRJ, 2007.

COMENIUS, Iohannis Amós. Didáctica Magna. Virtual Books, 2001. Disponível em: <http://www.ebooksbrasil.org/eLibris/didaticamagna.html>. Acesso em: 10 abr. 2013.

DEWEY, John. Vida e Educação. São Paulo: Melhoramentos, 1975.

FOUCAULT, Michel. Vigiar e Punir: nascimento das prisões. Petrópolis: Vozes, 1987.

FOUCAULT, Michel. Anti-Édipo: introdução à vida não-facista. In: DELEUZE, Gilles; GUATTARI, Félix. Anti-Édipo. Rio de Janeiro: Hólon Editorial, 1991. Disponível em: <https://pimentalab.milharal.org/files/2012/05/foucault_anti_ edipo.pdf $>$. Acesso em: 31 ago. 2013.

FOUCAULT, Michel. Resumo dos Cursos do Collège de France. Rio de Janeiro: Jorge Zahar, 1997.

Educação \& Realidade, Porto Alegre, v. 40, n. 4, p. 1169-1189, out./dez. 2015. 
FOUCAULT, Michel. A Ordem do Discurso: aula inaugural no Collège de France. São Paulo: Loyola, 2009.

FOUCAULT, Michel. Ditos e Escritos IX: genealogia da ética, subjetividade e sexualidade. Rio de Janeiro: Forense Universitária, 2014.

GHIRALDELLI Jr., Paulo. Didática e Teorias Educacionais. Rio de Janeiro: DP\&A, 2000.

KANT, Imanuel. Sobre a Pedagogia. Piracicaba: Unimep, 1996.

LOCKE, John. Alguns pensamentos acerca da Educação. Caderno de Educação da FaE/UFPel, Pelotas, UFPel, n.18, p. 147-171, 1999.

LOURO, Guacira Lopes. Gênero, Sexualidade e Educação: uma perspectiva pós-estruturalista. Petrópolis: Vozes, 1997.

LOURO, Guacira Lopes. Currículo, gênero e sexualidade: refletindo sobre o 'normal', o 'diferente' e o 'excêntrico'. Labrys, n. 1-2, 2002. Disponível em: <http://www.labrys.net.br/labrys1_2/guaciral.html>. Acesso em: 24 abr. 2012.

LYOTARD, Jean-François. A Condição Pós-Moderna. 8. ed. Rio de Janeiro: José Olympio, 2004.

MACEDO, Elizabeth. A Cultura e a Escola. In: MISKOLCI, Richard (Org.). Marcas da Diferença no Ensino Escolar. São Carlos: EdUFSCar, 2010. P. 11-43.

NELSON, Cary; TREICHLER, Paula A.; GROSSBERG, Lawrence. Estudos Culturais: uma introdução. In: SILVA, Tomaz Tadeu da (Org.). Alienígenas na Sala de Aula. Petrópolis: Vozes, 2008. P. 7-20.

PETERS, Michael. Pós-Estruturalismo e Filosofia da Diferença: uma introdução. Belo Horizonte: Autêntica, 2000.

REICH, Whilhelm. Psicologia de Massas do Fascismo. São Paulo: Martins Fontes, 1988.

SANTOS, Boaventura Souza. Para uma Pedagogia do Conflito. In: SILVA, Luiz Eron da et al. Novos Mapas Culturais, Novas Perspectivas Educacionais. Porto Alegre: Sulinas, 1996. P. 15-33.

SENNETT, Richard. A Corrosão do Caráter: consequências pessoais do trabalho no novo capitalismo. Rio de Janeiro: Record, 1999.

SIBILIA, Paula. Redes ou Paredes: a escola em tempos de dispersão. Tradução de Vera Ribeiro. Rio de Janeiro: Contraponto, 2012.

SILVA, Tomaz Tadeu da. O Adeus às Metanarrativas Educacionais. In: SILVA, Tomaz Tadeu da (Org.). O Sujeito da Educação: estudos foucaultianos. Petrópolis: Vozes, 1994. P. 247-258.

SKLIAR, Carlos. A Educação e a Pergunta Pelos Outros: diferença, alteridade, diversidade e os outros 'outros'. Ponto de Vista, Florianópolis, n. 5, p. 37-49, 2003.

SUCHODOLSKY, Bogdan. A Pedagogia e as Grandes Correntes Filosóficas. Lisboa: Livros Horizonte, 1978.

TAKARA, Samilo. Gênero e Blog: problematizações dos discursos de professoras e professores. 2013. 156 f. Dissertação (Mestrado em Educação) - Universidade Estadual de Maringá, Maringá, 2013.

TERUYA, Teresa Kazuko. Trabalho e Educação na Era Midiática. Maringá: Eduem, 2006.

TERUYA, Teresa Kazuko; TAKARA, Samilo; CASTELLAR, Taciana Marques. Caminhos de Uma Pedagogia Pós-Moderna. In: JORNADA DE ESTUDOS DO CURSO DE PEDAGOGIA A DISTÂNCIA - UEM, 2, 2012, Maringá. Anais... Maringá:

1188 Educação \& Realidade, Porto Alegre, v. 40, n. 4, p. 1169-1189, out./dez. 2015. 
2012. Disponível em: <http://www.nt5.net.br/publicacoes/24_Teresa_Teruya_ Samilo_Takara_Taciana_Castellar.pdf $>$. Acesso em: 31 mar. 2015.

VEIGA-NETO, Alfredo. Cultura, Culturas e Educação. Revista Brasileira de Educação, Rio de Janeiro, n. 23, p. 5-15, maio/ago. 2003. Disponível em: <http:// www.scielo.br/pdf/rbedu/n23/n23a01.pdf >. Acesso em: 31 mar. 2015.

VEIGA-NETO, Alfredo. Foucault e a Educação. Belo Horizonte: Autêntica, 2007. VEYNE, Paul. Foucault: seu pensamento, sua pessoa. Rio de Janeiro: Civilização Brasileira, 2011.

Samilo Takara é doutorando e mestre pelo Programa de Pós-Graduação em Educação da Universidade Estadual de Maringá. Graduado em Comunicação Social - Jornalismo pela Universidade Estadual do Centro-Oeste/PR. Bolsista Capes/Fundação Araucária.

E-mail: sami.takara@gmail.com

Teresa Kazuko Teruya é docente do Departamento de Teoria e Prática da Educação (DTP/UEM). Doutora em Educação pela Universidade Estadual Paulista Júlio de Mesquita Filho (UNESP/Marília). Pós-Doutorado pela UnB (Universidade de Brasília).

E-mail: tkteruya@gmail.com 